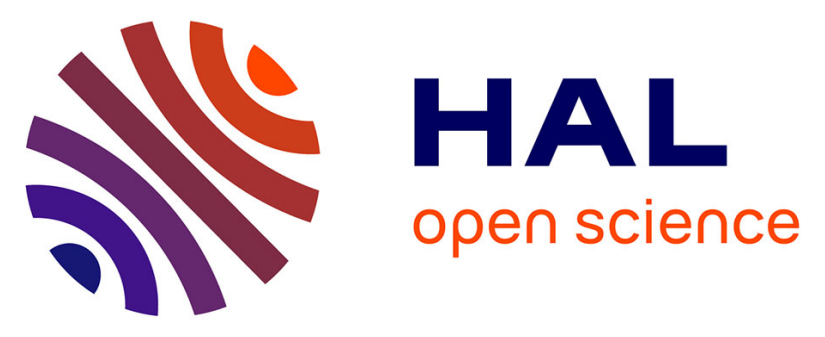

\title{
Azobased iminopyridine ligands and their rhenium metal complexes: Syntheses, spectroscopic, trans-cis photoisomerization and theoretical studies
}

Mohamed Ali Benmensour, Awatef Ayadi, Huriye Akdas-Kilig, Abdou Boucekkine, Jean-Luc Fillaut, Abdelkrim El-Ghayoury

\section{To cite this version:}

Mohamed Ali Benmensour, Awatef Ayadi, Huriye Akdas-Kilig, Abdou Boucekkine, Jean-Luc Fillaut, et al.. Azobased iminopyridine ligands and their rhenium metal complexes: Syntheses, spectroscopic, trans-cis photoisomerization and theoretical studies. Journal of Photochemistry and Photobiology A: Chemistry, 2019, 368, pp.78-84. 10.1016/j.jphotochem.2018.09.023 . hal-01943754

HAL Id: hal-01943754

https://hal-univ-rennes1.archives-ouvertes.fr/hal-01943754

Submitted on 4 Dec 2018

HAL is a multi-disciplinary open access archive for the deposit and dissemination of scientific research documents, whether they are published or not. The documents may come from teaching and research institutions in France or abroad, or from public or private research centers.
L'archive ouverte pluridisciplinaire HAL, est destinée au dépôt et à la diffusion de documents scientifiques de niveau recherche, publiés ou non, émanant des établissements d'enseignement et de recherche français ou étrangers, des laboratoires publics ou privés. 


\section{Azobased iminopyridine ligands and their rhenium metal complexes: syntheses, spectroscopic, trans-cis photoisomerization and theoretical studies}

Mohamed Ali Benmensour ${ }^{1}$, Awatef Ayadi ${ }^{2}$, Huriye Akdas-Kilig ${ }^{3}$, Abdou Boucekkine ${ }^{3 *}$, Jean-Luc Fillaut $^{3 *}$, Abdelkrim El-Ghayoury*2

${ }^{1}$ Département de chimie, Faculté des sciences, UMMTO, 15000 Tizi-Ouzou, Algeria and Laboratoire de thermodynamique et modélisation moléculaire, Faculté de chimie, USTHB, 16111 Bab Ezzouar, Alger, Algeria ${ }^{2}$ Laboratoire MOLTECH-Anjou, Université d'Angers, UMR 6200 CNRS, UFR Sciences, Bât. K, 2 Bd. Lavoisier, 49045 Angers, France

${ }^{3}$ Univ Rennes, CNRS, ISCR - UMR 6226, F-35000 Rennes, France

*E-mail: abdelkrim.elghayoury@univ-angers.fr; jean-luc.fillaut@univ-rennes1.fr; abdou.boucekkine@univrennes1.fr

\section{Graphical Abstract}

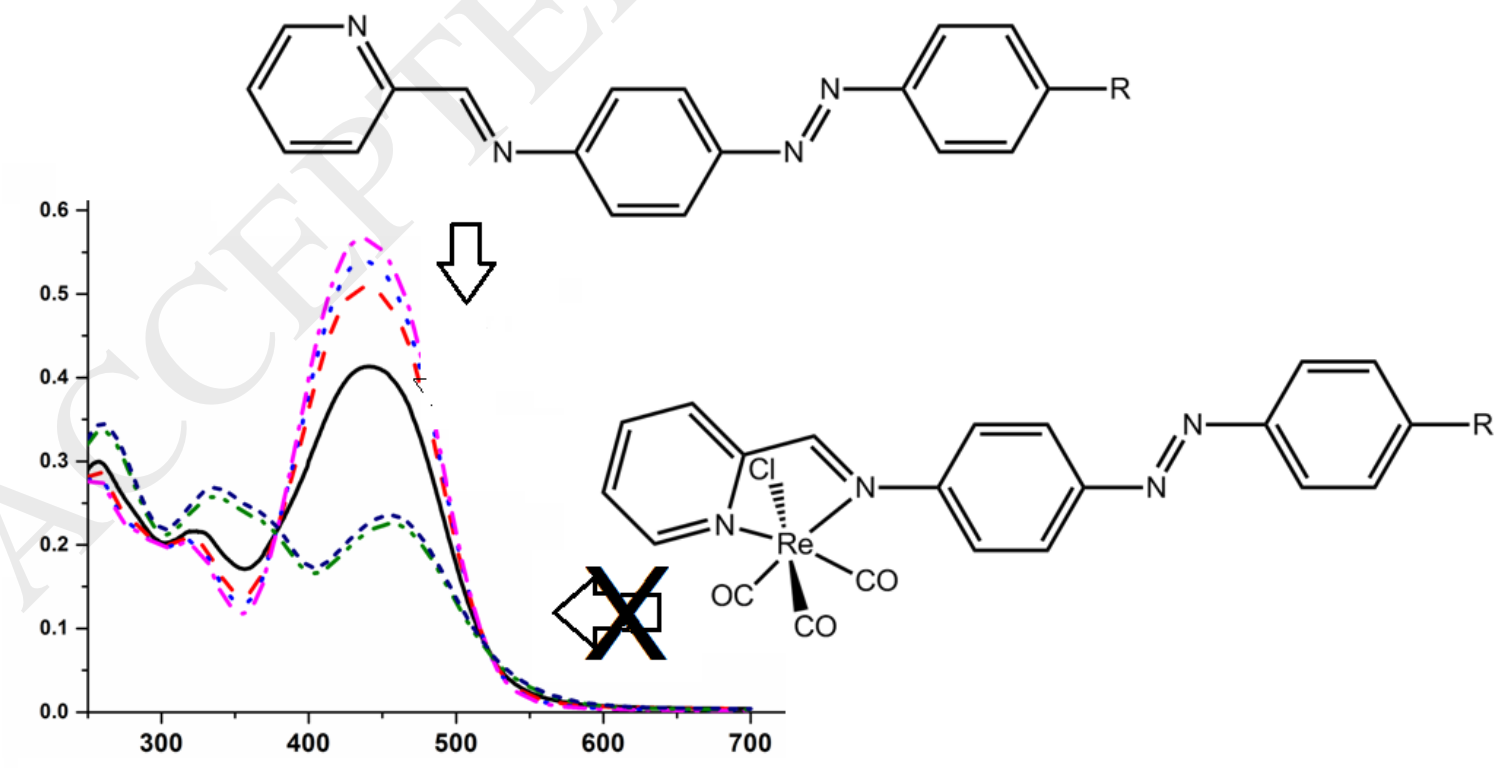


Highlights

- Two rhenium metal complexes have been prepared and structurally characterized

- Absorption spectra have been measured

- DFT calculations have been performed to support the experimental results

- Photoisomerization studies of the azo group in the ligands and in the metal complexes have been performed.

\section{Abstract}

The reaction of rhenium(I) pentacarbonyl chloride $\operatorname{Re}(\mathrm{CO}){ }_{5} \mathrm{Cl}$ with N,N-dimethyl-4-((E)-(pyridin-2ylmethylene) amino)phenyl) diazenyl) aniline $\mathbf{L} 1$ and (E)-4-((E)-(4-nitrophenyl)diazenyl)-N-(pyridin-2ylmethylene) aniline $\mathbf{L} 2$ affords two rhenium metal complexes $\left[\operatorname{ReL1}(\mathrm{CO})_{3} \mathrm{Cl}\right](\operatorname{ReL1})$ and $\left[\operatorname{ReL2}(\mathrm{CO})_{3} \mathrm{Cl}\right]$ (ReL2) , respectively. These $\operatorname{Re}(\mathrm{I})$ complexes were characterized in detail, including their single crystal structures, absorption spectra and electronic structures using DFT calculations. Trans to cis photoisomerization of the free ligands and complexes was investigated experimentally and rationalized theoretically. Interestingly, light-induced photoisomerization of the azo fragment is observed for free ligand $\mathbf{L} \mathbf{1}$ while inhibition of this process is produced upon coordination to Re metal cation.

Keywords: Iminopyridine; Azobenzene; UV-Visible spectroscopy; Rhenium complex; X-ray diffraction; DFT.

\section{Introduction}

Increasing interest is currently devoted to the photochemistry of transition metal derivatives incorporating stimuli-responsive functions for their potential applications in photonic memory, photosensing, as well as luminescence imaging [1]. In particular, photochromic metal complexes allow the specific properties of the metal center and the optical response of the photochromic group to be combined. Of course, the photoinduced isomerization of azobenzene and its derivatives is one of the most and well-studied light driven processes. The location of the azobenzene unit in the ligands has 
been established as an important factor to influence the photochromic properties of azobenzene containing transition metal complexes [2-5]. The isomerization is assumed to take place from intraligand excited states localized on the azobenzene unit. Meanwhile, the choice of the metal center also participates to the photochromic properties of these azobenzene containing complexes [6]. It would be of great interest to better identify the factors which favor an efficient synergy between the intrinsic properties of the metal complex and that of the photochromic unit.

Our interest recently focused on the possible effects of coordination of iminopyridine azo-based ligands to heavy transition metals on the photochemistry of these ligands. For instance, it has been reported that organoplatinum complexes containing iminopyridine azo-based ligands can undergo trans-cis isomerization of the azo group [7]. In this context, we were interested in the photochemistry of $\operatorname{Re}(I)$ polypyridyl complexes having iminopyridine-appended azobenzene ligands. Rhenium(I) tricarbonyl polypyridine complexes generally possess attractive photophysical and photochemical properties such as large Stokes shifts, long emission lifetimes, and high photostability through the coordination of functionalized ligands. In the present paper, we aim to report on the synthesis and full characterization, including X-ray diffraction analysis, of two rhenium metal complexes. The focus of this work is on the trans-cis photoisomerization behavior of the free ligands, L1 and L2, (scheme 1) [8] and of the corresponding complexes ReL1 and ReL2. These studies are supported by DFT and TD-DFT computational studies that reveal the importance of relevant barriers on the potential energy surfaces in the $\mathrm{S} 1$ excited states, which involve conical intersection, for rationalizing the observed behaviours.

\section{Experimental}

\subsection{General remarks}

All manipulations were performed under nitrogen atmosphere using commercial grade solvents. Rhenium(I) pentacarbonyl chloride was of reagent grade quality and used as received. NMR spectra were recorded on a Bruker Avance DRX 300 spectrometer operating at $300 \mathrm{MHz}$ for ${ }^{1} \mathrm{H}$ and 75 $\mathrm{MHz}$ for ${ }^{13} \mathrm{C}$. Chemical shifts are expressed in parts per million (ppm) downfield from external TMS. The following abbreviations are used: $s$, singlet; $d$, doublet; $t$, triplet; td, triplet of doublet. UV-visible spectra were recorded at room temperature in quartz cuvettes using Perkin-Elmer spectrophotometer. Mass spectra were collected with Bruker Biflex-III TM. IR spectra were recorded on a Bruker vertex 70.

\subsection{Crystallography}

X-ray single-crystal diffraction data for both complexes were collected on an Agilent SuperNova diffractometer equipped with Atlas CCD detector and mirror monochromated micro-focus Cu K $\alpha$ radiation $(\lambda=1.54184 \AA$ ). The two structures were solved by direct methods, expanded and refined on $\mathrm{F}^{2}$ by full matrix least-squares techniques using SHELX97 programs (G.M. Sheldrick, 1998). 
All non- $\mathrm{H}$ atoms were refined anisotropically and the $\mathrm{H}$ atoms were included in the calculation without refinement. Multiscan empirical absorption was corrected using the CrysAlisPro program (CrysAlisPro, Agilent Technologies, V1.171.37.35g, 2014). Crystallographic data for the structural analysis have been deposited with the Cambridge Crystallographic Data Centre, CCDC 1837472 for complex ReL1 and CCDC 1837473 complex ReL2. Details about data collection and solution refinement are given in Table S1.

\subsection{Synthesis of ReL1 and ReL2 metal complexes}

\subsubsection{Synthesis of Rhenium(I) complex $\left[\operatorname{ReL1}(\mathrm{CO})_{3} \mathrm{Cl}\right](\operatorname{ReL1})$}

To a solution of $\mathbf{L} \mathbf{1}(0.01 \mathrm{~g}, 0.03 \mathrm{mmol})$ in a solution of toluene and dichloromethane $(3: 1, \mathrm{v} / \mathrm{v})$ was added $\left[\operatorname{Re}(\mathrm{CO})_{5} \mathrm{Cl}\right](0.016 \mathrm{~g}, 0.045 \mathrm{mmol})$. The mixture was refluxed for 6 hours under nitrogen atmosphere. After cooling the resulting mixture to room temperature, the solvent was removed by a rotary evaporator. The dark residue was extracted with dichloromethane and recrystallized from acetone/hexane to yield complex ReL1 as brown crystals with $90 \%$ yield ( $0.017 \mathrm{~g}, 0.027 \mathrm{mmol}) ; \mathrm{mp}$

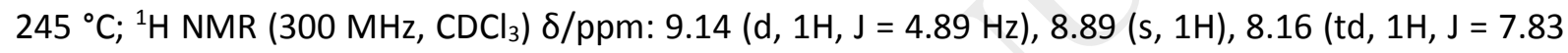
$\mathrm{Hz}, \mathrm{J}=1.39 \mathrm{~Hz}), 8.06(\mathrm{~m}, 1 \mathrm{H}), 8.02(\mathrm{~d}, 2 \mathrm{H}, \mathrm{J}=8.7 \mathrm{~Hz}), 7.96(\mathrm{~d}, 2 \mathrm{H}, \mathrm{J}=8.83 \mathrm{~Hz}), 7.66(\mathrm{~m}, 3 \mathrm{H}), 6.82(\mathrm{~d}, 2 \mathrm{H}$, $\mathrm{J}=9.04 \mathrm{~Hz}), 3.17(\mathrm{~s}, 6 \mathrm{H}) .{ }^{13} \mathrm{C} \mathrm{NMR}\left(75 \mathrm{MHz}, \mathrm{CDCl}_{3}\right) \delta / \mathrm{ppm}: 165.6,155.7,155.3,154.9,153.5,153.3$, 152.9, 151.9, 151.8, 139.3, 132.2, 129.1, 129, 126.3, 126.2, 124.1, 123.2, 123.1, 122.8, 111.9, 111.7, 40.5, 40.4. Selected IR bands (cm ${ }^{-1}$ ): 2017 (CO), 1897 (CO), 1860 (CO), 1595, 1519, 1357, 1125, 819, 788, 554, 495. Anal. calcd for $\mathrm{C}_{23} \mathrm{H}_{19} \mathrm{~N}_{5} \mathrm{O}_{3} \mathrm{ClRe}$ : $\mathrm{C}, 43.50 ; \mathrm{H}, 3.02 ; \mathrm{N}, 11.03$, found: $\mathrm{C}, 43.31 ; \mathrm{H}, 2.87 ; \mathrm{N}$, 10.79. MALDI-TOF MS calcd: $m / z=635.0$ Da. found: $m / z=635.3$; HR-MS (M): calcd for $\mathrm{C}_{23} \mathrm{H}_{19} \mathrm{~N}_{5} \mathrm{O}_{3} \mathrm{ClRe}$ : 635.0734; found: 635.0736 .

\subsubsection{Synthesis of Rhenium(I) complex $\left[\operatorname{ReL2}(\mathrm{CO})_{3} \mathrm{Cl}\right](\operatorname{ReL2})$}

This complex was prepared by following the same procedure as for complex 1 . Yield: $88 \%(0.017 \mathrm{~g}$,

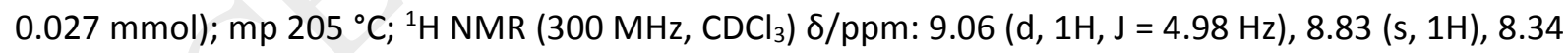
$(\mathrm{d}, 2 \mathrm{H}, \mathrm{J}=8.83 \mathrm{~Hz}), 8.03(\mathrm{~m}, 6 \mathrm{H}), 7.64(\mathrm{~m}, 3 \mathrm{H}) .{ }^{13} \mathrm{C} \mathrm{NMR}\left(75 \mathrm{MHz}, \mathrm{CDCl}_{3}\right)$ 8/ppm: 166.6, 155.4, 155.1, 153.5, 153.0, 152.3, 149.1, 139.4, 129.5, 129.4, 124.9, 124.84, 123.7, 123.3. Selected IR bands (cm $\left.{ }^{-1}\right)$ : 2014 (CO), 1888 (CO), 1879(CO), 1578, 1519, 1342, 1102, 859, 781, 553, 450. Anal. calcd for $\mathrm{C}_{21} \mathrm{H}_{13} \mathrm{~N}_{5} \mathrm{O}_{5} \mathrm{ClRe}$ : $\mathrm{C}, 39.59 ; \mathrm{H}, 2.06 ; \mathrm{N}, 10.99$, found: $\mathrm{C}, 39.28 ; \mathrm{H}, 1.99 ; \mathrm{N}, 10.83$. MALDI-TOF MS calcd: $\mathrm{m} / \mathrm{z}=637.0$ Da. found: $\mathrm{m} / \mathrm{z}=637.1$; HR-MS (M): calcd for $\mathrm{C}_{21} \mathrm{H}_{13} \mathrm{~N}_{5} \mathrm{O}_{5} \mathrm{ClRe}$ : 637.0163; found: 637.0161 .

\section{Results and discussion}

\subsection{Syntheses}

The equimolar reaction between $\mathbf{L} \mathbf{1}$ or $\mathbf{L} 2$ and the $\left[\operatorname{Re}(\mathrm{CO})_{5} \mathrm{Cl}\right]$ precursor at refluxing toluene/dichloromethane mixture, under inert atmosphere, afforded the mononuclear neutral 
rhenium(I) metal complexes $\operatorname{ReL1}$ and $\operatorname{ReL2}$ (scheme 1), described as $\left[\operatorname{ReL1}(\mathrm{CO}){ }_{3} \mathrm{Cl}\right]$ and $\left[\operatorname{ReL2}(\mathrm{CO}){ }_{3} \mathrm{Cl}\right]$ respectively as a brown precipitate for ReL1 and as an orange precipitate for ReL2.

\subsection{Description of crystal structures}

Single crystals of ReL1 and ReL2 metal complexes were obtained by recrystallization from acetone/hexane solutions. Crystal structures are represented in Fig. 1. Both ReL1 and ReL2 complexes crystallize in the triclinic space group P-1 with one independent molecule in the unit cell.

Both ligands $\mathbf{L} \mathbf{1}$ and $\mathbf{L} \mathbf{2}$ acquired a cis-conformation of the iminopyridyl group, within the complexes. The rhenium center is surrounded by the bidentate iminopyridyl chelating fragment, three carbonyl groups, and a chlorine atom and its coordination sphere presents the expected, although slightly distorted, octahedral geometry. This minor distortion from the ideal octahedral geometry is caused by the formation of a five-membered chelate ring (the $\mathrm{N}-\mathrm{Re}-\mathrm{N}$ angle) [9]. The structures of both complexes highlight the expected facial arrangement of the three carbonyl ligands. For both complexes, the values corresponding to cis angles around the $\operatorname{Re}(I)$ ion are very close to the ideal value of $90^{\circ}$. Meanwhile, the N-Re1-N angle shows significantly lower values, $74.33(2)^{\circ}$ and $74.69(1)^{\circ}$ for ReL1 and ReL2 respectively, as imposed by the small N-N bite distance of a $\alpha$-iminopyridyl type ligand (average values for ReL1 and ReL2 respectively). The dihedral angle between the iminopyridyl fragment and the adjacent phenyl ring of the azobenzene unit is equal to $32.80^{\circ}(3)$ for $\operatorname{ReL} 1$ and to $42.67^{\circ}(3)$ for $\operatorname{ReL2}$.

Within the crystal structure of ReL1 the Re-N distances (Re-N4 $=2.206(5) \AA ̊, \operatorname{Re}-\mathrm{N} 5=2.177(5) \AA)$ are similar to those found in complexes of the $\left\{\operatorname{ReX}(\mathrm{CO})_{3}\right\}$ fragment with the iminopyridyl based coordinating group (Table S2 and Figure S1 in supplementary information) [10-12]. All three Re-CO bond lengths are very close, and the $\mathrm{Re}-\mathrm{C}-\mathrm{O}$ angles present minor deviations from linear structure, values ranging from $\left(177.50(9)^{\circ}\right.$ to $\left.177.78(8)^{\circ}\right)$.

In the crystal structure of $\operatorname{ReL2}$ complex, the ligands surrounding the $\operatorname{Re}(I)$ ion are also involved in hydrogen bonding interactions type. Thus, two of the three $\mathrm{CO}$ ligands establish short $\mathrm{C}-\mathrm{H} \cdots \mathrm{O}$ contacts $(\mathrm{H} 11 \cdots \mathrm{O} 12.600(6) \AA \AA \mathrm{H} 15 \cdots \mathrm{O} 2$ 2.550(5) $\AA$ ) with hydrogen atoms from pyridine linking neighbor molecules into layers parallel with the ac crystallographic plane (Fig. S2).

\subsection{UV-Visible absorption spectroscopy}

The UV-visible absorption spectra (Fig. 3 and Fig. 4) of the two ligands $\mathbf{L} \mathbf{1}$ and $\mathbf{L} \mathbf{2}$ and their corresponding metal complexes ReL1 and ReL2 were recorded in dichloromethane solution ( C = 5.9.10-5 M) at room temperature. As previously reported [8], ligand $\mathbf{L} 1$ exhibits two strong absorption bands at $\lambda=266 \mathrm{~nm}$ and $438 \mathrm{~nm}$ that are assigned to the $\pi \rightarrow \pi^{*}$ and $\mathrm{n} \rightarrow \pi^{*}\left({ }^{1}\right.$ ILCT) transitions together with a slight intramolecular charge transfer (ICT) from the donating dimethylamino donor to the 
accepting iminopyridine unit. The spectrum of ReL1 complex shows the same characteristics as ligand L1 with a bathochromic shift and a broadening of the visible absorption band. The bathochromic shift (ca. $40 \mathrm{~nm}$ ) indicates an increase of the electron acceptor character of the iminopyridyl fragment upon complexation with rhenium (I) which acts as a strong Lewis acid while the broadening of the band can be assigned to the presence of of a metal to ligand charge transfer $\operatorname{Re}(\mathrm{d} \pi) \rightarrow \operatorname{ligand}\left(\pi^{*}\right){ }^{1} \mathrm{MLCT}$ transition [13]. We assume that, in ReL1, the two absorption bands corresponding to the ${ }^{1}$ ILCT and ${ }^{1} \mathrm{MLCT}$ are superimposed. These features are confirmed by means of the TD-DFT computations which have been carried out (vide infra).

In the case of ligand $\mathbf{L 2}[8]$ a strong absorption band around $380 \mathrm{~nm}$ assigned to $\pi-\pi^{*}$ and $\mathrm{n}-\pi^{*}$ transitions is observed. In the case of ReL2, because of the presence of a nitro electron withdrawing group in $\mathbf{L 2}$, the absorption band in the visible region is blue-shifted, by comparison with $\mathbf{L} \mathbf{2}$, while a broad absorption band, of lower intensity $\left(\varepsilon=4500 \mathrm{~L} \cdot \mathrm{mol}^{-1} \cdot \mathrm{cm}^{-1}\right)$ is observed in the visible region around $\lambda_{\max }=452 \mathrm{~nm}$ which is characteristic of a metal to ligand charge transfer $\left(\operatorname{Re}(\mathrm{d} \pi) \rightarrow \operatorname{ligand}\left(\pi^{*}\right)\right.$ ${ }^{1} \mathrm{MLCT}$ transition [13]. Note that no significant emission behavior has been observed for the two rhenium complexes.

\subsection{Photoisomerization studies}

It is well known that azobenzenes experience a trans-cis isomerization by irradiation at a light wavelength close to their absorption maxima [14]. L1, L2 (that can be considered as being push-pull azobenzenes (ppAB) types [13]) and their corresponding rhenium complexes were systematically studied in order to establish if trans-cis isomerization occurs in these systems.

Fig. 2 exhibits the UV-visible absorption spectra of L1 in dichloromethane, showing drastic modifications of the UV-visible absorption spectra upon irradiation at $450 \mathrm{~nm}$ revealing the photoisomerization of the azobenzene chromophore in L1. Upon irradiation the intensity of the absorbance at $440 \mathrm{~nm}$, attributed to the $\pi-\pi^{*}$ transition of the trans-azobenzene group, decreased gradually, reaching a relatively stable value at a maximum wavelength of $460 \mathrm{~nm}$. At the same time, the intensity of a new signal in the $300-400 \mathrm{~nm}$ range, which we assign to the $\pi-\pi^{*}$ transition of the cis isomer, increased, leading to two isobestic points at 380 and $530 \mathrm{~nm}$ for L1. These variations are consistent with the trans-cis isomerization of the azobenzene group in L1, as described for similar compounds [15], and at the photostationary state, the intensity of the main absorption band collapsed by a factor approximately 3. Indeed, the TD-DFT simulations of the UV-visible spectra of the trans and cis isomers of L1 (Fig. S3), which compare very well with the observed ones, confirms the occurrence of the transcis isomerization under irradiation. 
In the case of ligand $\mathbf{2} \mathbf{2}$ we did not observe any photoisomerization, whatever is the solvent (dichloromethane or acetonitrile).

For complexes ReL1 and ReL2 we did not observe any change of the absorption spectra in acetonitrile or in dichloromethane under irradiation or in the dark. The trans-to-cis photoisomerization property is completely switched off for the complex ReL1, compared to the ligand L1. Clearly, the photoisomerization dynamics is strongly influenced by the conjugation pathway and modified upon coordination of a metal to the azobenzene containing conjugated ligand, as previously demonstrated by Fillaut and coworkers for a series of Ruthenium(II) tris(bipyridine) complexes [16]. More recently Freixa and coworkers reported Iridium(III) cyclometalated complexes, in which the use of an aliphatic spacer unit between the azobenzene and the coordinating unit of the ligand allowed the electronic communication to be disrupted and the observation of photochromic properties for these coordination complexes [2].

\subsection{Simulated UV-Visible absorption spectra and theoretical calculations}

All calculations were performed at the DFT level of theory, employing the G09 suite of programs [17]. Based on the results of several previous studies on similar systems, the B3LYP [18-20] and CAM-B3LYP functionals $[21,22]$ have been chosen to perform the computations. The 6-31G(d) and LanL2DZ basis set [23] augmented with polarization function on all atoms, except hydrogen ones, have been used for the ligands and their corresponding complexes respectively. Solvent effects were taken into account using the polarisable continuum model (PCM) [24]. All ground state geometries were optimized at these levels of theory and checked to be true minima on the potential energy surface, the computed frequencies of the normal modes of vibration being all real. Then, time-dependent density functional theory (TD-DFT) [25] computations were performed, using the optimized ground state geometries, to obtain excitation energies and simulate the UV-visible spectra of the considered species.

The simulated UV-visible spectra of the considered ligands and complexes agree very well with the observed ones, when using the CAM-B3LYP functional, so that our discussion will be based on the CAM-B3LYP results only. This reliability of the CAM-B3LYP functional for the UV-visible spectra simulation has already been observed in the case of the ligands [8].

First, we observe that the band shifts observed for the UV-visible spectra upon complexation are well reproduced by the computations, namely the bathochromic one in the case of the complexation of ligand $\mathbf{L} \mathbf{1}$ and the hypsochromic one in the case of ligand L2 (Fig. 3 and Fig. 4). 
The results of the TD-DFT computations which permit the assignment of the UV-visible absorption bands of the ligands are given in Table 1.

${ }^{\mathrm{a}} \mathrm{H}=\mathrm{HOMO} ; \mathrm{L}=\mathrm{LUMO}$

The assignments of the observed UV-visible bands of the free $\mathbf{L} \mathbf{1}$ and $\mathbf{L} \mathbf{2}$ ligands have been described in reference [8]. To consider the photoisomerization issue, the properties of the free $\mathbf{L} \mathbf{1}$ and $\mathbf{L} \mathbf{2}$ ligands are compared to those of their corresponding complexes, reminding that ligand $\mathbf{L} \mathbf{1}$ only undergoes the trans to cis isomerization. The first excited states of both $\mathbf{L} \mathbf{1}$ and $\mathbf{L} \mathbf{2}$ derive from transitions involving the diazo group, thus likely to trigger the trans-cis photoisomerization of the azobenzene group. Indeed, HOMO-2 of L1 and HOMO-1 of L2, exhibit a diazo lone pair character, whereas the reached MOs upon excitation, namely LUMO and LUMO+1 for L1, LUMO and LUMO+2 for L2 are $\pi$ type MOs (Fig. 5), so that the computed excitations at $431 \mathrm{~nm}$ for $\mathbf{L} \mathbf{1}$ and $\mathbf{4 6 8} \mathrm{nm}$ for $\mathbf{L} \mathbf{2}$ exhibit mainly a $\mathrm{n}-\pi^{*}$ character. However, the oscillator strength of the electronic transition is ca. $\mathbf{0 . 0 0 5 0}$ for $\mathbf{L} \mathbf{1}$ and $c a$. 0.0001 for $\mathbf{L} \mathbf{2}$ which is very low, fifty times smaller than that for $\mathbf{L} \mathbf{1}$. This is certainly a factor contributing to the fact that ligand $\mathbf{L} \mathbf{2}$ does not exhibit a photoisomerization, contrarily to ligand $\mathbf{L} 1$. It is worth noting that in our previous TD-DFT study of the ligands [8] we were interested in the UV-visible spectra only so that the electronic transitions of low oscillator strength were not considered. These latter transitions, i.e. HOMO-2 to LUMO for L1 and HOMO-1 to LUMO for L2 are of importance (vide supra) for the isomerization processes, explaining why they are considered now.

The assignment of the UV-visible absorption bands of the ReL1 and ReL2 complexes has also been done on the basis of the TD-DFT results given in Table 2 and Table 3 whereas the frontier MO diagrams of these species are displayed on Fig. 6.

For the ReL1 complex, the computed excitation at $431 \mathrm{~nm}$ exhibits an $n-\pi^{*}$ character, the involved occupied molecular orbital HOMO-4 is localized on the diazo function (Table 2). This excitation is similar to that computed for the ligand L1, but with a lower oscillator strength. However, it appears that this complex does not isomerize under irradiation contrarily to ligand L1. Thus, for ReL2, we observe the same situation as for the ligand $\mathbf{L} \mathbf{2}$ alone; the computed excitation at $467 \mathrm{~nm}$ exhibits an $n-\pi^{*}$ character with a very low oscillator strength of $c a$. 0.0007 , the involved occupied HOMO-4 being localized on the azo function (Table 2). Similarly to the $\mathbf{L} \mathbf{2}$ ligand, the relevant excited state will not be easily reached and then the photoisomerization should hardly be possible.

Another interesting difference appears between the UV-visible spectra of ReL1 and ReL2, when considering the most intense absorption band computed at $419 \mathrm{~nm}$ for ReL1 and at $354 \mathrm{~nm}$ for ReL2. Contrarily to ReL1, the absorption band of ReL2 exhibits a significant MLCT character, since the weight of the metal in the involved occupied MOs of the corresponding transitions (Table 4) namely HOMO 
of ReL1, is ca. $0.15 \%$ whereas for the HOMO-2 of ReL2, this weight is ca. $26 \%$. In the case of ReL1 the two excitations at 395 and $374 \mathrm{~nm}$ with a smaller oscillator strength exhibit also a MLCT character, the metal weights in the corresponding occupied MOs being equal to $c a$. $50 \%$ and $48 \%$ respectively. The low intensity bands computed at $402 \mathrm{~nm}$ and $380 \mathrm{~nm}$ of ReL2 exhibit also an important MLCT character. Finally, it is interesting to note that whereas the HOMO of ReL2 has an important metallic character (ca. 49\%) it is not the case for ReL1, mainly due to the strong donating character of the $\mathrm{NMe}_{2}$ group of the L1 ligand which contributes strongly to push the ligand HOMO to higher energies than the metallic MO.

Considering in more details the photoisomerization issue, the ligand and the complexes behaviors have been investigated. The photoisomerization of azobenzene in solution has already been studied experimentally and by means of theoretical calculations [26-28]. It has been found theoretically that the isomerization from the trans conformation to the cis one after the $n-\pi^{*}$ vertical excitation, occurs on the S1 potential energy surface (PES), in three steps. The first two steps correspond to a relaxation to a local minimum, then to an intermediate state through an energy barrier. The third step corresponds to a S1 $\rightarrow$ S0 relaxation via a conical intersection (CI) S1 / S0 with an energy barrier of 12 $\mathrm{kJ} / \mathrm{mol}$, towards the trans to cis isomerization [26].

Note that in the singlet ground state (SO) the ligands are more stable in a trans conformation. The energy barrier between the two trans and cis forms is high in the ground state (SO) up to about 50 $\mathrm{kcal} / \mathrm{mol}$. Interestingly, we found that the trans structure undergoes a distortion in the S1 state leading to a non-planar structure of the phenyl azo moiety. Therefore, we determined for the two ligands the minima on the S1 PES, then we identified for each ligand intermediate (I-cis and I-trans) and transition states on this S1 PES using the QST2 method, in order to estimate the energy barriers between the cis forms and the TSs. Moreover, as expected [26-28] we observed the occurrence of a conical intersection, namely that the minimum energy structure on the S1 PES corresponds to a TS on the ground state SO PES.

According to Fig. 7, we note that the intermediate I-cis (S1) state of $\mathbf{L 2}$, although lower in energy than the $\mathrm{TS}(\mathrm{S} 1)$ is higher in energy than the $\min (\mathrm{S} 1)=\mathrm{TS}(\mathrm{S} 0)$ so that the relaxation of this intermediate via the S1/S0 CI leads to the trans conformation, whereas for L1 (Fig. 7), the intermediate I-cis (S1) state is lower in energy than the $\min (\mathrm{S} 1)=\mathrm{TS}(\mathrm{S} 0)$; then, the relaxation of this intermediate leading to a cis conformation is facilitated. There is also another difference between $\mathbf{L 1}$ and $\mathbf{L 2}$, which is the cis to trans backward barrier on S1; as shown in Fig. 7 and Fig. 8, the barrier in the case of $\mathbf{L 2}$ is ca. $5.8 \mathrm{kcal} / \mathrm{mol}$ which is lower than that for $\mathbf{L} \mathbf{1}$ (23.8 
$\mathrm{kcal} / \mathrm{mol}$ ) so that the latter ligand cannot undergo the reverse cis-trans conversion. Thus, either on the S1 PES or via the conical intersection, the trans-cis isomerization appears to be highly favoured for the $\mathbf{L} \mathbf{1}$ ligand contrarily to the $\mathbf{L} 2$ one, thus explaining the observed facts.

We have also explored the PES for the two ReL1 and ReL2 complexes; these complexes are more stable in the singlet ground state (S0) in a trans conformation, whereas in the S1 PES this conformation is distorted as already observed for the ligands. In the same way as for the ligands, we have located for each complex the transition state (TS), and then the energy barrier (cis-TS). We found that these complexes behave as ligand L2. Indeed, the backward cis to trans barrier is low, ca. $4 \mathrm{kcal} / \mathrm{mol}$ for ReL1 and is $c a .6 \mathrm{kcal} / \mathrm{mol}$ for $\mathbf{R e L 2}$, thus of the same order of magnitude as $\mathbf{L} 2(5.8 \mathrm{kcal} / \mathrm{mol})$. We think that this low energy barrier can explain the nonphotoisomerization for the two complexes, since it is likely to allow the return from cisconformation to trans-conformation.

We have also investigated theoretically the isomerization process in the triplet state reminding that in our case, the experiments which have been carried out do not involve this excited state. The obtained computational results show the same trend as observed for the ligands, namely that the triplet state as well, should allow the trans-cis isomerization for the $\mathbf{L} \mathbf{1}$ ligand but not for $\mathbf{L} \mathbf{2}$ and the complexes.

\section{Conclusions}

In this paper, we describe the synthesis, full characterization and the theoretical studies of two new rhenium complexes ReL1 and ReL2, L1 and $\mathbf{L} \mathbf{2}$ being azo-based iminopyridine ligands. The UV-visible spectrophotometric data show a red shift for complex ReL1 indicating an increase of the electron acceptor behavior of the iminopyridine fragment in ligand $\mathbf{L} \mathbf{1}$ upon complexation with $\operatorname{Re}(\mathrm{I})$ and a blue shift for complex ReL2 with appearance of new broad absorption band in the visible region indicating the occurrence of a MLCT transition. The observed bands were fully assigned using the TD-DFT results. The distinct behaviors of the ligands and complexes regarding the trans-cis photoisomerization process have been rationalized, using DFT and TD-DFT computations. Several parameters have been considered for that, among them the relevant barriers on the potential energy surfaces in the S1 excited states, which involve conical intersection. 


\section{Acknowledgements.}

We acknowledge the HPC resources of CINES and of IDRIS under the allocations 2017[x2015080649] and 2018-[x2016080649] made by GENCI (Grand Equipement National de Calcul Intensif).

\section{References}

[1] J. Otsuki, T. Akasaka, K. Araki, Molecular switches for electron and energy transfer processes based on metal complexes. Coord. Chem. Rev. 252 (2008) 32-56.

[2] J. Pérez-Miqueo, A. Altube, E. García-Lecina, A. Tron, N. D. McClenaghan, Z. Freixa, Photoswitchable azobenzene-appended iridium(iii) complexes. Dalton Trans. 45 (2016) 13726-13741.

[3] Y. Hasegawa, T. Nakagawa, T. Kawai, Recent progress of luminescent metal complexes with photochromic units. Coord. Chem. Rev. 254 (2010) 2643-2651.

[4] B. Tylkowski, A. Trojanowska, V. Marturano, M. Nowak, L. Marciniak, M. Giamberini, V. Ambrogi, P. Cerruti, Power of light - Functional complexes based on azobenzene molecules. Coord. Chem. Rev. 351 (2017) 205217.

[5] S. Kume, H. Nishihara, Metal-based Photoswitches Derived from Photoisomerization. In Photofunctional Transition Metal Complexes; Yam, V. W., Ed.; Structure and Bonding; Springer Berlin Heidelberg, 123 (2007) pp 79-112.

[6] H. Nishihara, Combination of redox-and photochemistry of azo-conjugated metal complexes. Coord. Chem. Rev. 249 (2005) 1468-1475.

[7] M. E. Moustafa, M. S. McCready, R. J. Puddephatt, Switching by Photochemical trans-cis Isomerization of Azobenzene Substituents in Organoplatinum Complexes. Organometallics 31 (2012) 6262-6269.

[8] A. Ayadi, D.-G. Branzea, M.-A. Benmensour, A. Boucekkine, N. Zouari, A. El-Ghayoury, Azo-based iminopyridine ligands: synthesis, optical properties, theoretical calculations and complexation studies, Tetrahedron, 71 (2015) 7911-7919.

[9] A. Pino-Cuevas, R. Carballo, L. Muñoz, E.M. Vázquez-López, Rhenium Complexes of Ligands Based on Stilbene -Synthesis, Characterization, Reactivity, and Conformational Analysis, Eur. J. Inorg. Chem. (2015) 4402-4411. 
[10] N. M. Shavaleev, Z. R. Bell, G. Accorsi, M. D. Ward, Syntheses and structures of mononuclear $\{\operatorname{Re}(\mathrm{CO}) 3 \mathrm{Cl}(\mathrm{NN})\}$ 'complex ligands' with a pendant imino-pyridine binding site, and preparation of some heterodinuclear Re(I)-lanthanide(III) complexes, Inorg. Chim. Acta 351 (2003) 159-166.

[11] C. M. Alvarez, R. García-Rodríguez, D. Miguel, Carbonyl complexes of manganese, rhenium and molybdenum with 2-pyridylimino acid ligands, J. Organomet.Chem. 692 (2007) 5717-5726.

[12] K. Pramanik, M. S. Jana, S. Kundu, T. K. Mondal, Re(I) carbonyl complexes of N-[(2-pyridyl)methyliden]- $\alpha$ (or ß)-aminonaphthalene: Synthesis, structure, electrochemistry and DFT analysis, J. Mol. Struct. 1017 (2012) 19-25.

[13] N. Dominey, B. Hauser, J. Hubbard, J. Dunham, Structural, spectral, and charge-transfer properties of $\mathrm{ClRe}(\mathrm{CO}) 3(2-\mathrm{PP})[2-\mathrm{PP}=\mathrm{N}$-(2-pyridinylmethylene)phenylamine $]$ and $\mathrm{Cl} \operatorname{Re}(\mathrm{CO}) 3(2-\mathrm{PC})[2-\mathrm{PC}=\mathrm{N}-(2-$ pyridinylmethylene)cyclohexylamine], Inorg. Chem. 30 (1991) 4754-4758.

[14] H. M. D. Bandara, S. C. Burdette, Photoisomerization in different classes of azobenzene, Chem. Soc. Rev. 41 (2012) 1809-1825.

[15] M. G. Mohamed, W.-C. Su, Y.-C. Lin, C.-F. Wang, J.-K. Chen, K.-U. Jeong, S.-W. Kuo, Azopyridinefunctionalized benzoxazine with $\mathrm{Zn}(\mathrm{ClO} 4) 2$ form high-performance polybenzoxazine stabilized through metal-ligand coordination, RSC Advances 4 (2014) 50373-50385.

[16] A. Amar, P. Savel, H. Akdas-Kilig, C. Katan, H. Meghezzi, A. Boucekkine, J.-P. Malval, J.-L. Fillaut, Photoisomerization in Aminoazobenzene-Substituted Ruthenium(II) Tris(bipyridine) Complexes: Influence of the Conjugation Pathway, Chem. Eur. J. 21 (2015) 8262-8270.

[17] M. J. Frisch, G. W. Trucks, H. B. Schlegel, G. E. Scuseria, M. A. Robb, J. R. Cheeseman, G. Scalmani, V. Barone, B. Mennucci and G. A. Petersson, Gaussian09, 2015.

[18] C. Lee, W. Yang, R. G. Parr, Development of the Colle-Salvetti correlation-energy formula into a functional of the electron density, Phys. Rev. B 37 (1998) 785-789.

[19] A. D. J. Becke, Density-functional thermochemistry. III. The role of exact exchange, Chem. Phys. 98 (1993) 5648-5652.

[20] P. J. Stephens, F. J. Devlin, C. F. Chabalowski, M. J. Frisch, Ab Initio Calculation of Vibrational Absorption and Circular Dichroism Spectra Using Density Functional Force Fields, J. Phys. Chem. 98 (1994) 11623-11627.

[21] T. Yanai, D. P. Tew, N. C. Handy, A new hybrid exchange-correlation functional using the Coulombattenuating method (CAM-B3LYP), Chem. Phys. Lett. 393 (2004) 51-57.

[22] D. J. Tozer, N. C. Handy, Improving virtual Kohn-Sham orbitals and eigenvalues: Application to excitation energies and static polarizabilities, J. Chem. Phys. 109 (1998) 10180-10189. 
[23] P. J. Hay, W. R. Wadt, Ab initio effective core potentials for molecular calculations. Potentials for K to Au including the outermost core orbitals, J. Chem. Phys. 82 (1985) 299-310.

[24] V. Barone, M. Cossi, J. Tomasi, A new definition of cavities for the computation of solvation free energies by the polarizable continuum model, J. Chem. Phys. 107 (1997) 3210-3221.

[25] M. E. Casida, In Recent Advances in Density Functional Methods; D. P. Chong, Ed.; World Scientific: Singapore, 1 (1995) p 155.

[26] E. Wei-Guang Diau, A New Trans-to-Cis Photoisomerization Mechanism of Azobenzene on the S1(n, $\left.\pi^{*}\right)$ Surface, J. Phys. Chem. A 108 (2004) 950-956.

[27] C.-W. Chang, Y.-C. Lu, T.-T. Wang, E. Wei-Guang Diau, Photoisomerization Dynamics of Azobenzene in Solution with S1 Excitation: A Femtosecond Fluorescence Anisotropy Study, J. Am. Chem. Soc. 126 (2004) 10109-10118.

[28] M. Quick, A. L. Dobryakov, M. Gerecke, C. Richter, F. Berndt, I. N. loffe, A. A. Granovsky, R. Mahrwald, N. P. Ernsting, S. A. Kovalenko, Photoisomerization Dynamics and Pathways of trans- and cis-Azobenzene in Solution from Broadband Femtosecond Spectroscopies and Calculations, J. Phys. Chem B 118 (2014) 87568771. 


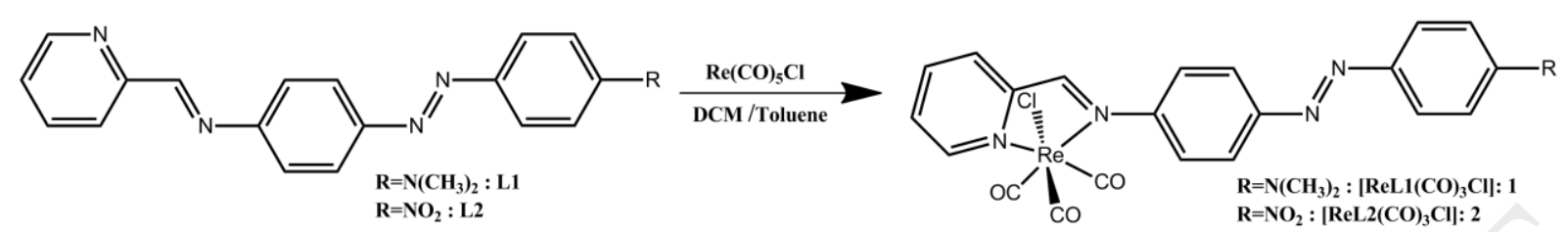

Scheme 1. Synthetic route of rhenium complexes ReL1 and ReL2.

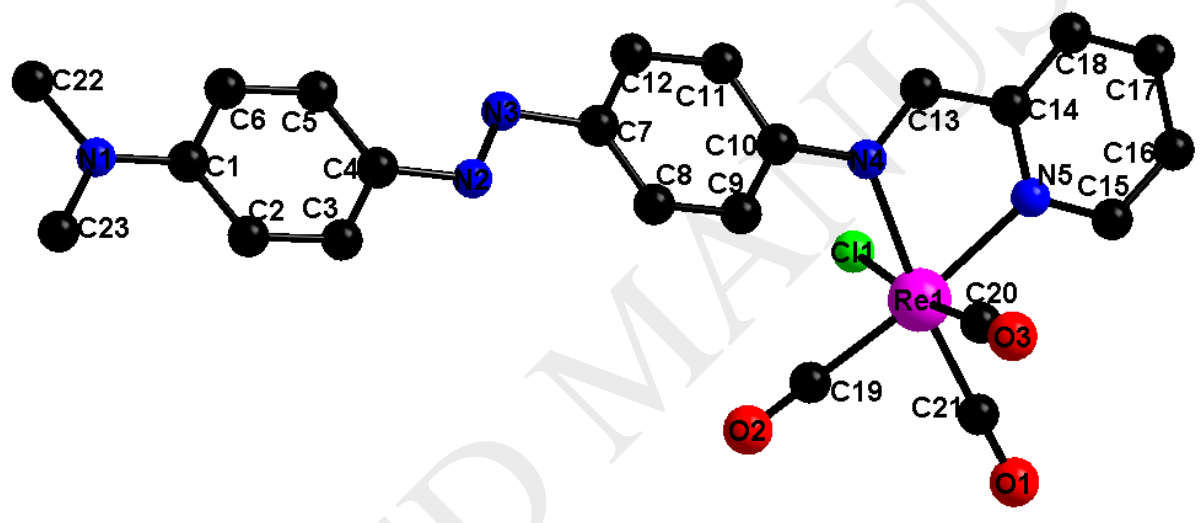

(ReL1)

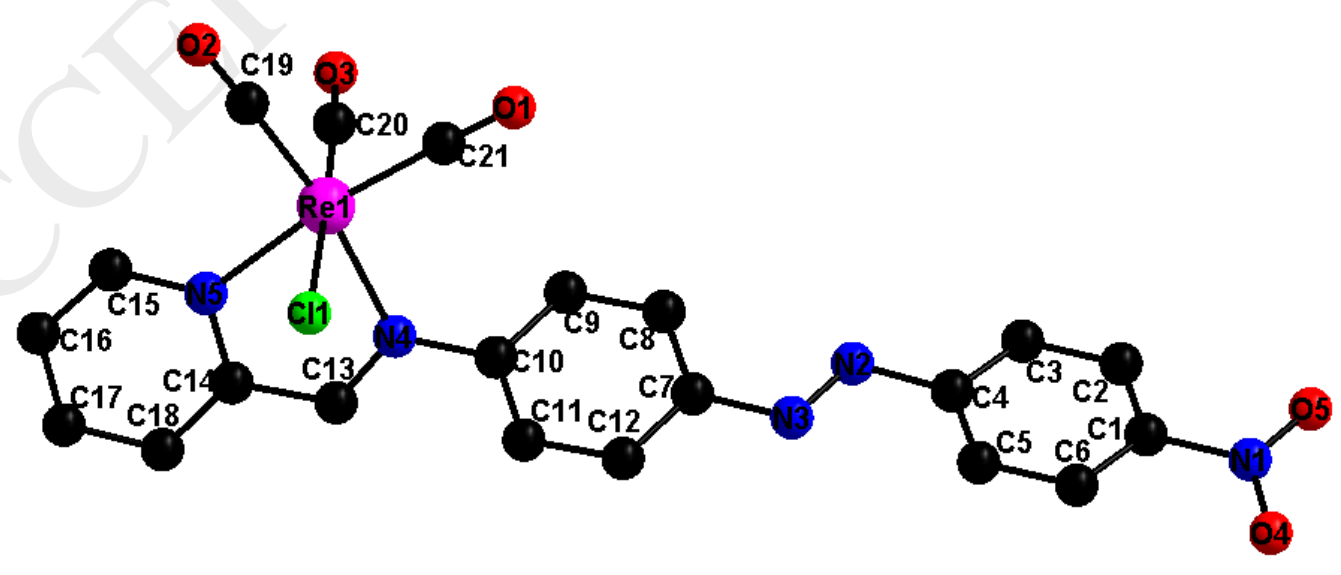

(ReL2) 
Fig. 1. Crystal structure of ReL1 and ReL2 complexes with atom numbering scheme. Hydrogen atoms were omitted for clarity.

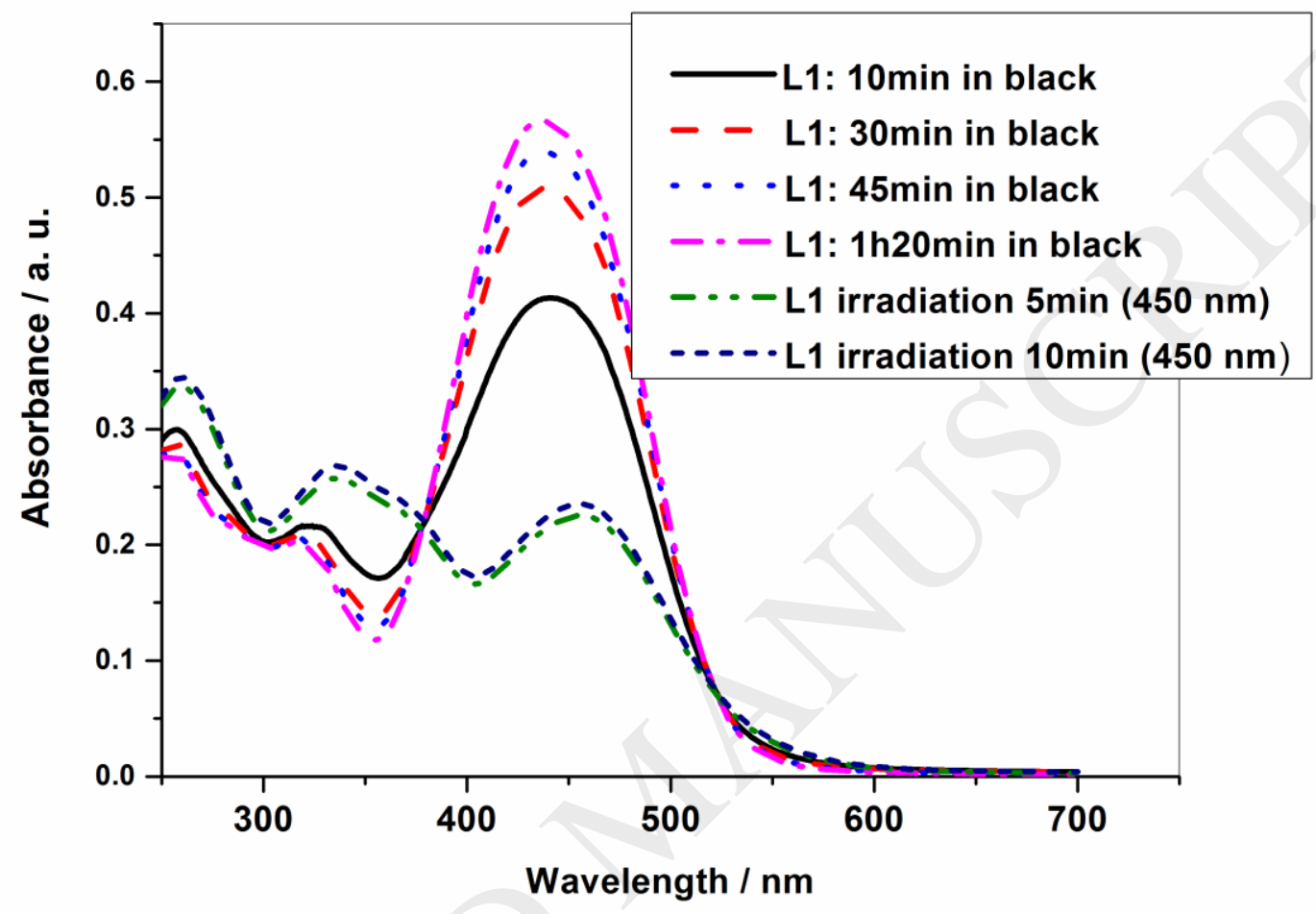

Fig. 2. Changes in the UV-Visible absorption spectra upon irradiation a $450 \mathrm{~nm}$ of ligand $\mathbf{L} \mathbf{1}$ in $\mathrm{CH}_{2} \mathrm{Cl}_{2}$. 


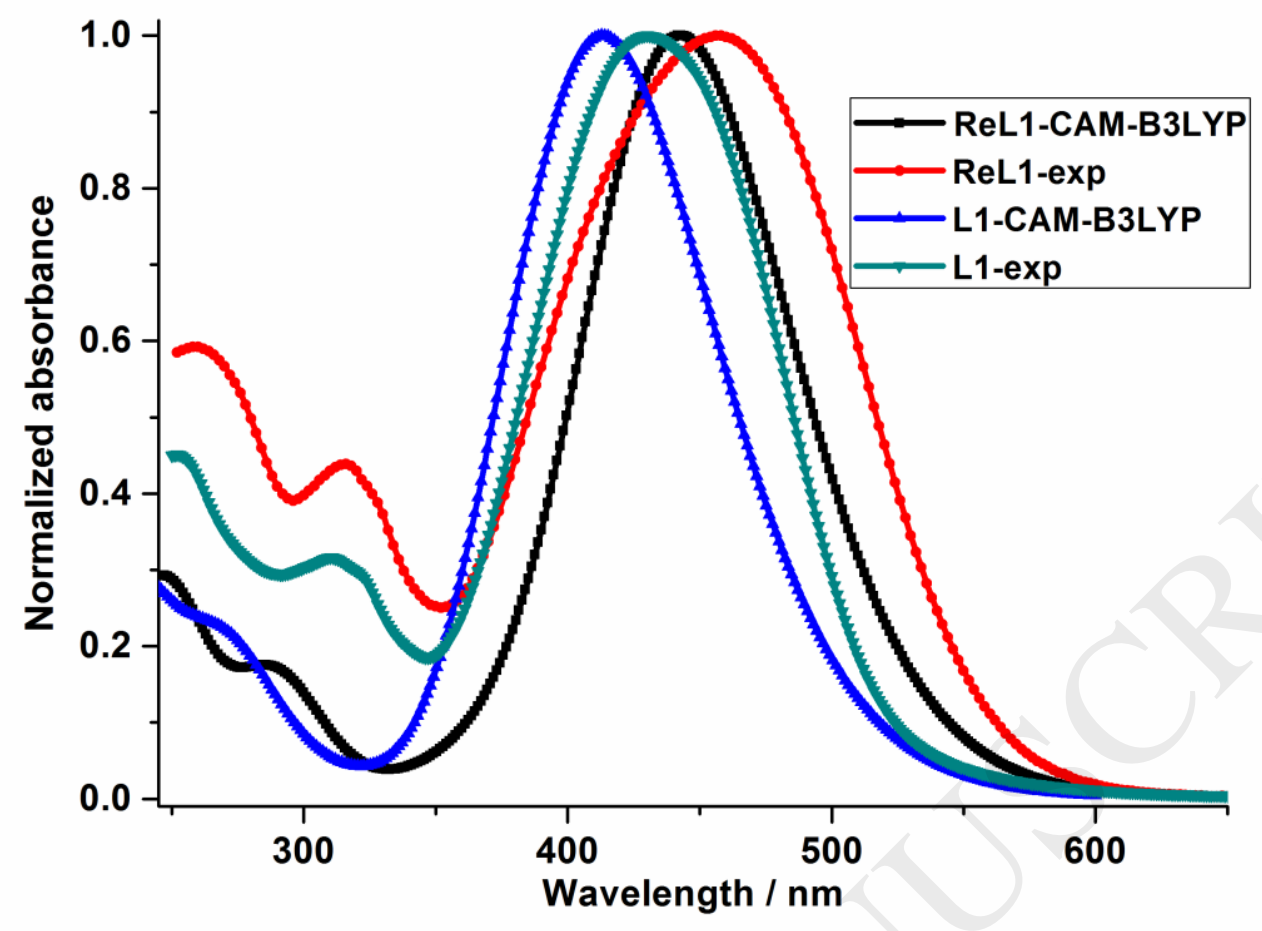

Fig. 3. Experimental $\left(C=2 \cdot 5 \cdot 10^{-5} \mathrm{M}\right)$ and simulated UV-Visible absorption spectra of ligand $\mathbf{L} \mathbf{1}$ and ReL1 complex (in dichloromethane solution at room temperature) 


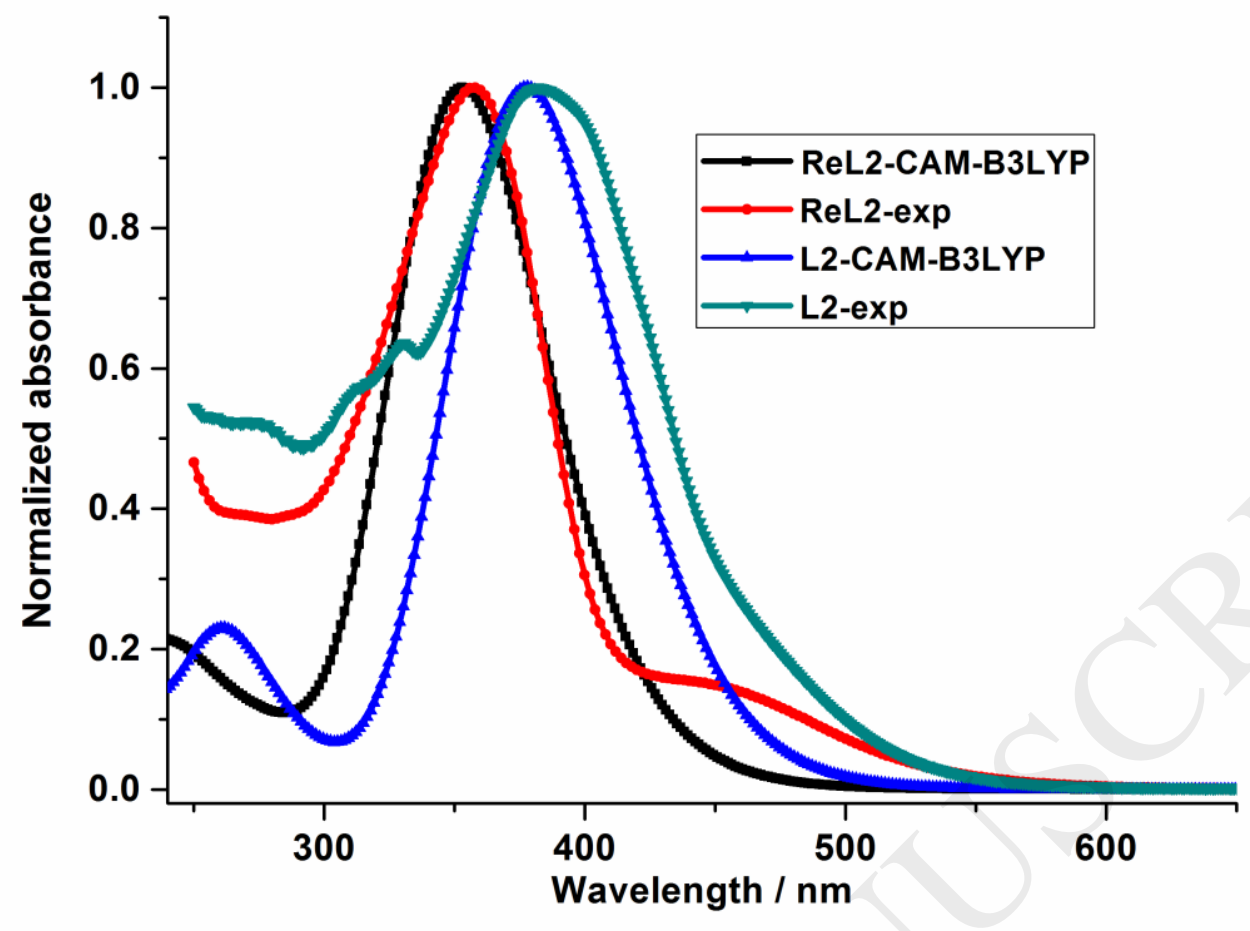

Fig. 4. Experimental $\left(C=2 \cdot 5 \cdot 10^{-5} \mathrm{M}\right)$ and simulated UV-Visible absorption spectra of ligand $\mathbf{L} \mathbf{2}$ and ReL2 complex (in dichloromethane solution at room temperature) 


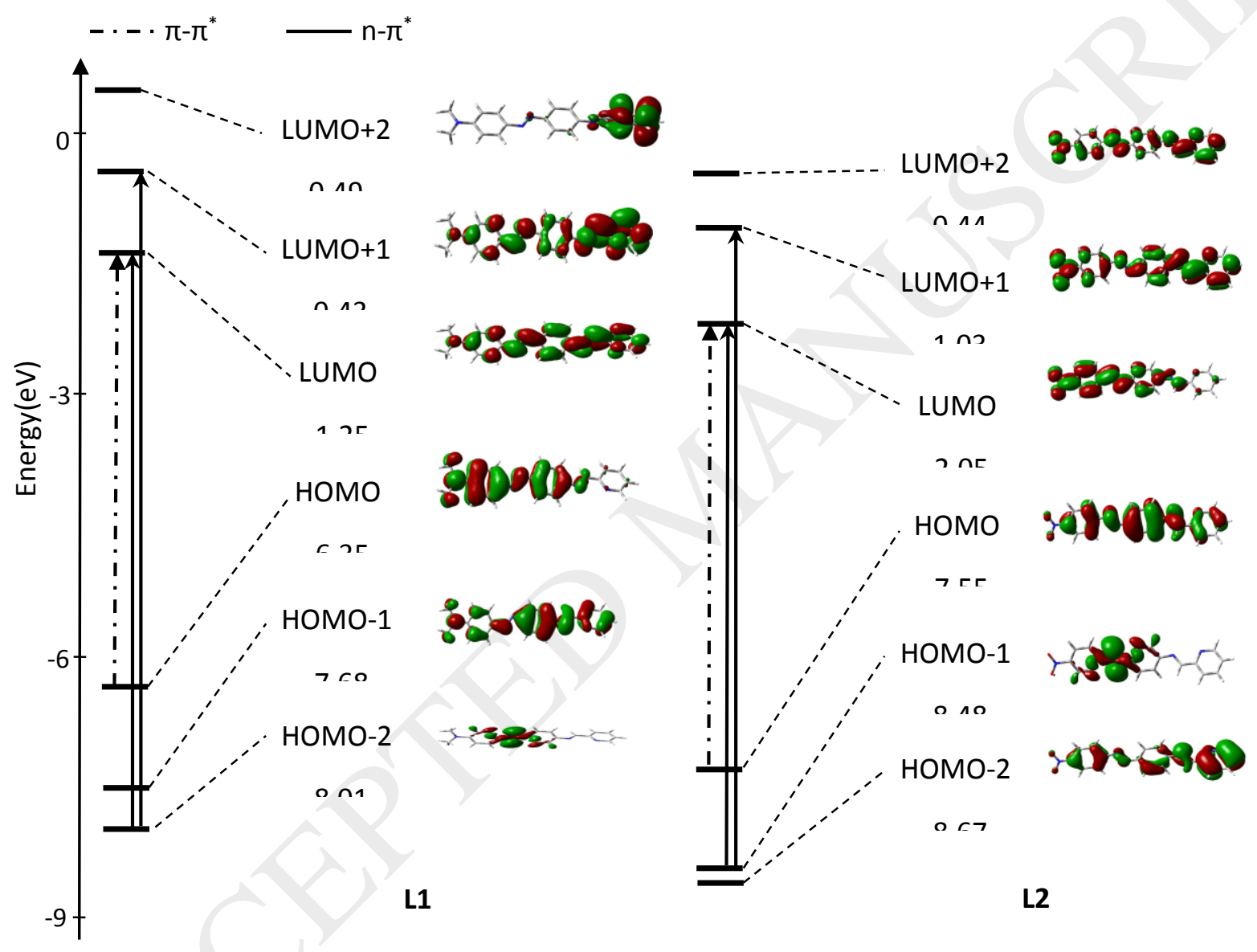

Fig. 5. Frontier MO diagrams of ligands $\mathbf{L} 1$ and $\mathbf{L} 2$ with main transitions (CAM-B3LYP level). 


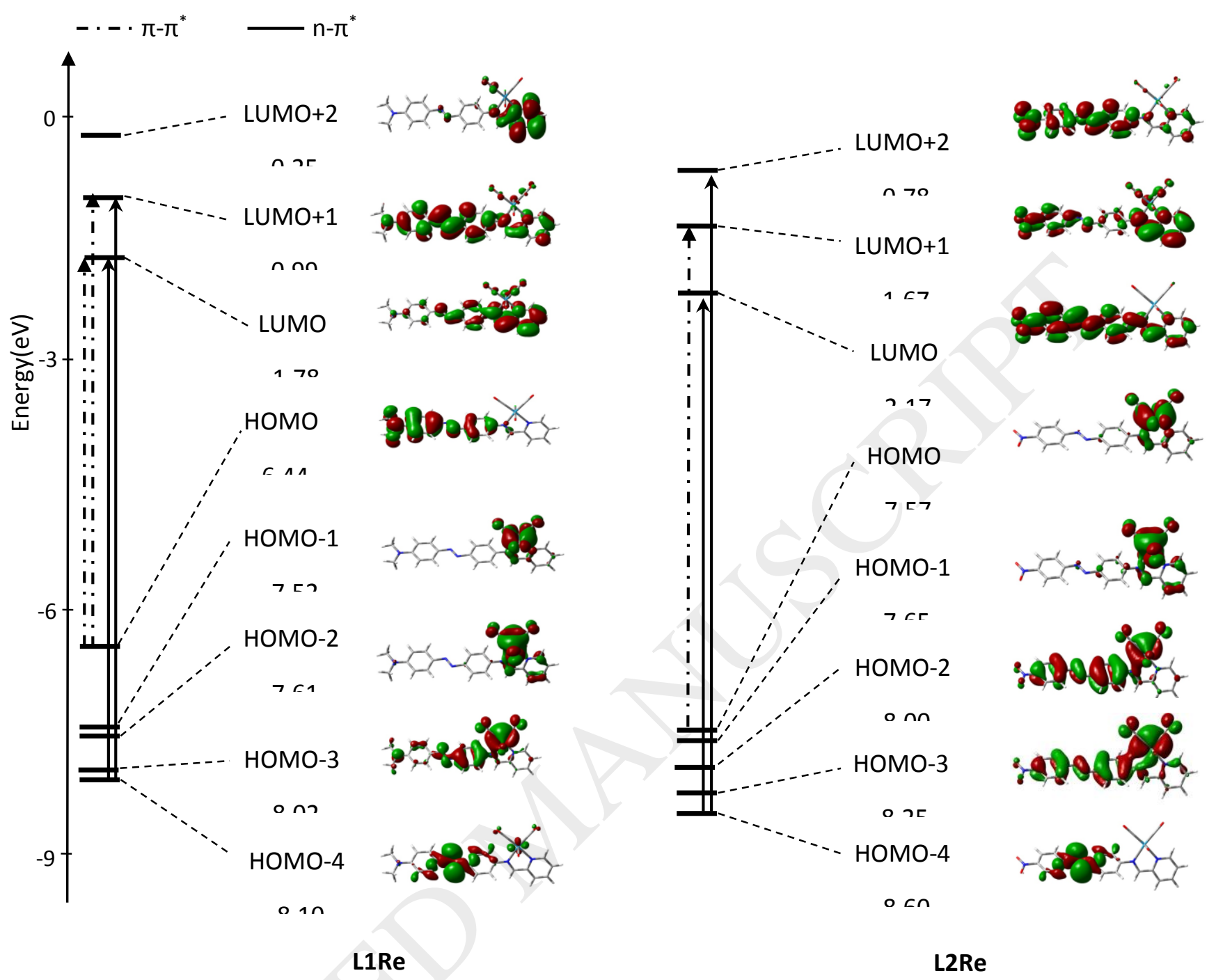

Fig. 6. Frontier MO diagrams of complexes ReL1 and ReL2 with main transitions (CAM-B3LYP level). 


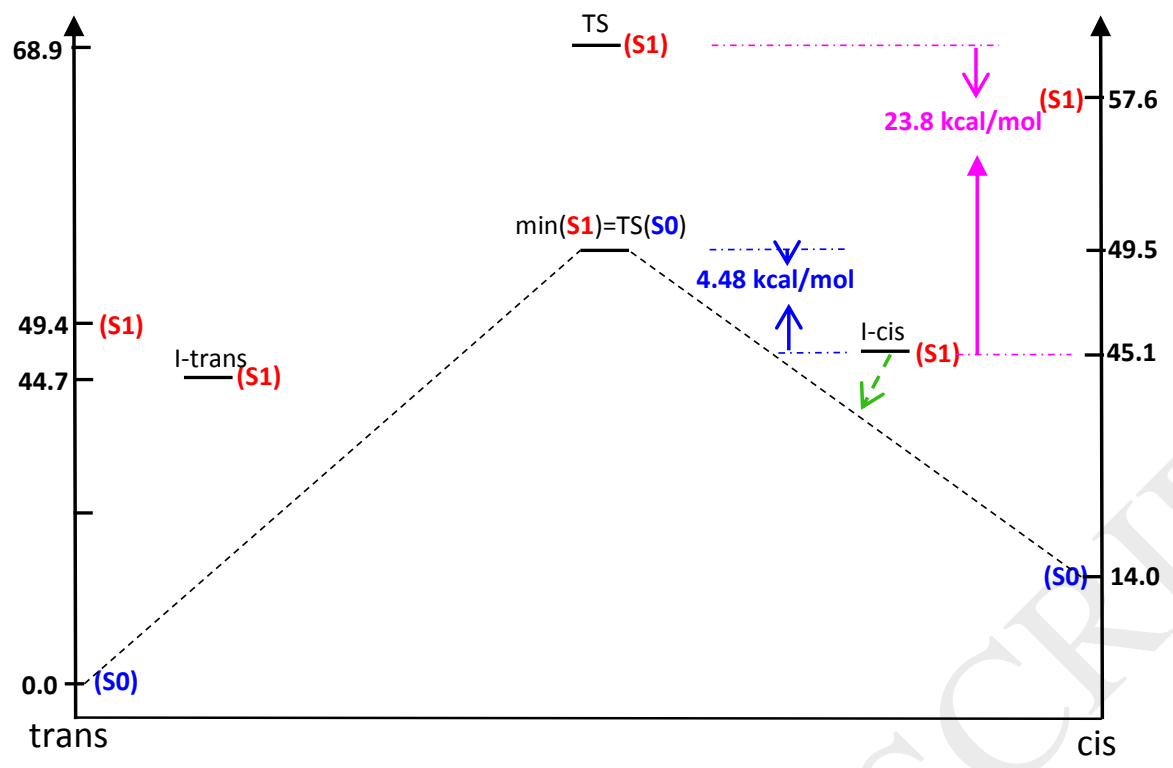

Fig. 7. Energy diagram of L1 (kcal/mol; CAM-B3LYP level) 


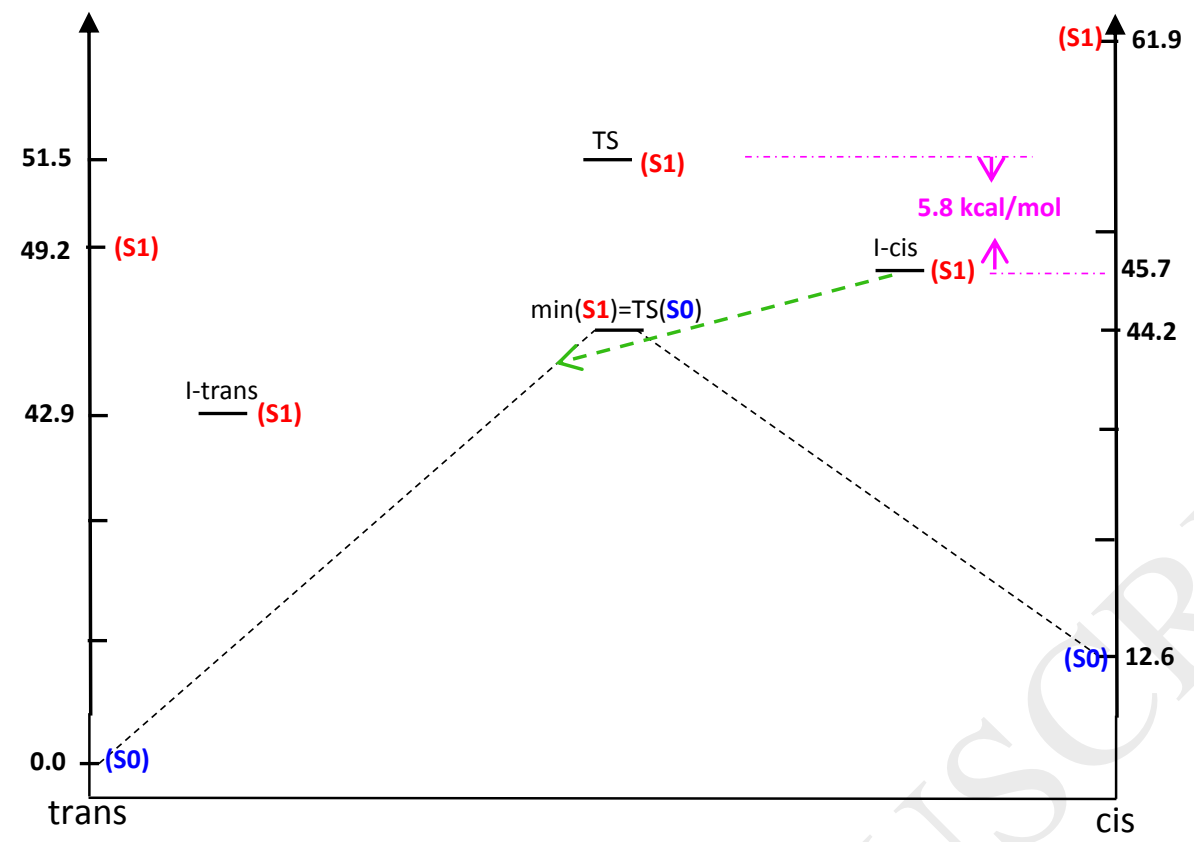

Fig. 8. Energy diagram of $\mathbf{L 2}$ ( $\mathrm{kcal} / \mathrm{mol}$; CAM-B3LYP level) 
Table 1. TD-DFT results (absorption wavelengths, oscillator strengths) for the ligands

\begin{tabular}{|c|c|c|l|}
\hline Compounds & $\lambda$ in $\mathrm{nm}(\Delta E$ in $\mathrm{eV})$ & \multicolumn{1}{|c|}{ Main transitions $^{\mathrm{a}}$} \\
\hline & $431(2.87)$ & 0.0050 & $\mathrm{H}-2 \rightarrow \mathrm{L}(72 \%) \mathrm{H}-2 \rightarrow \mathrm{L}+1(23 \%)$ \\
& $418(2.97)$ & 1.7858 & $\mathrm{H} \rightarrow \mathrm{L}(85 \%)$ \\
& $315(3.93)$ & 0.0204 & $\mathrm{H}-1 \rightarrow \mathrm{L}(33 \%) \mathrm{H} \rightarrow \mathrm{L}+1(32 \%)$ \\
& & & \\
\hline \multirow{2}{*}{ L1 } & $468(2.65)$ & 0.0001 & $\mathrm{H}-1 \rightarrow \mathrm{L}(76 \%) \mathrm{H}-1 \rightarrow \mathrm{L}+2(16 \%)$ \\
& $383(3.23)$ & 1.6871 & $\mathrm{H} \rightarrow \mathrm{L}(84 \%) \mathrm{H}-2 \rightarrow \mathrm{L}(10 \%)$ \\
& & & \\
\hline
\end{tabular}

${ }^{\mathrm{a}} \mathrm{H}=\mathrm{HOMO} ; \mathrm{L}=\mathrm{LUMO}$

Table 2. TD-DFT results for the complexes

\begin{tabular}{|c|c|c|l|}
\hline Compounds & $\lambda(\mathrm{nm})$ & $f$ & \multicolumn{1}{|c|}{ Main transitions } \\
\hline \multirow{3}{*}{ ReL1 } & 431 & 0.0030 & $\mathrm{H}-4 \rightarrow \mathrm{L}(67 \%) \mathrm{H}-4 \rightarrow \mathrm{L}+1(21 \%)$ \\
& 419 & 1.4566 & $\mathrm{H} \rightarrow \mathrm{L}(52 \%) \mathrm{H} \rightarrow \mathrm{L}+1(35 \%)$ \\
& 395 & 0.0805 & $\mathrm{H}-1 \rightarrow \mathrm{L}(85 \%)$ \\
& 374 & 0.0823 & $\mathrm{H}-2 \rightarrow \mathrm{L}(88 \%)$ \\
\hline \multirow{3}{*}{ ReL2 } & 467 & 0.0007 & $\mathrm{H}-4 \rightarrow \mathrm{L}(68 \%) \mathrm{H}-4 \rightarrow \mathrm{L}+2(21 \%)$ \\
& 402 & 0.0114 & $\mathrm{H} \rightarrow \mathrm{L}+1(59 \%) \mathrm{H} \rightarrow \mathrm{L}(36 \%)$ \\
& 380 & 0.1444 & $\mathrm{H}-1 \rightarrow \mathrm{L}+1(57 \%) \mathrm{H}-1 \rightarrow \mathrm{L}(37 \%)$ \\
& 354 & 1.2107 & $\mathrm{H}-2 \rightarrow \mathrm{L}(69 \%)$ \\
\hline
\end{tabular}


Table 3. Rhenium, metal group and azo percentage weights in frontier molecular orbitals

\begin{tabular}{|c|c|c|c|c|}
\hline MO & compounds & Rhenium weight \% & $\begin{array}{c}\text { Metal group } \\
\text { weight } \%\end{array}$ & $\begin{array}{c}\text { Azo group } \\
\text { weight \% }\end{array}$ \\
\hline \multirow{2}{*}{ LUMO+2 } & ReL1 & 0.49 & 2.74 & 1.14 \\
\hline & ReL2 & 0.83 & 2.15 & 22.93 \\
\hline \multirow{2}{*}{ LUMO+1 } & ReL1 & 1.29 & 3.67 & 37.78 \\
\hline & ReL2 & 2.24 & 5.9 & 2.70 \\
\hline \multirow{2}{*}{ LUMO } & ReL1 & 2.18 & 5.50 & 5.92 \\
\hline & ReL2 & 0.5 & 1.26 & 23.20 \\
\hline \multirow{2}{*}{ HOMO } & ReL1 & 0.15 & 0.28 & 8.60 \\
\hline & ReL2 & 49.14 & 91.67 & 0.19 \\
\hline \multirow{2}{*}{ HOMO-1 } & ReL1 & 49.75 & 94.02 & 0.09 \\
\hline & ReL2 & 47.24 & 89.36 & 0.33 \\
\hline \multirow{2}{*}{ HOMO-2 } & ReL1 & 47.93 & 91.71 & 0.14 \\
\hline & ReL2 & 26.29 & 31.94 & 6.92 \\
\hline \multirow{2}{*}{ HOMO-3 } & ReL1 & 44.00 & 54.32 & 6.05 \\
\hline & ReL2 & 44.45 & 77.07 & 4.19 \\
\hline \multirow{2}{*}{ HOMO-4 } & ReL1 & 1.91 & 02.01 & 73.23 \\
\hline & ReL2 & 0.17 & 0.53 & 76.47 \\
\hline
\end{tabular}

${ }^{a}$ Metal group $=\operatorname{Re}(\mathrm{CO})_{3} \mathrm{Cl}$ 